\title{
Mucinous Cystadenocarcinoma
} of the Breast with Estrogen Receptor Expression: \section{A Case Report and Review of the Literature}

\author{
Sema Rakıcı ${ }^{a}$ Güzin Gönüllüb Ş. Bilge Gürsel \\ Levent Yıldız $^{d} \quad$ i. Koray Bayrak ${ }^{\mathrm{e}} \quad$ İdris Yücel ${ }^{b}$ \\ aDepartment of Radiation Oncology, Atatürk University Faculty of Medicine, \\ Erzurum, Departments of ${ }^{\mathrm{b}}$ Medical Oncology, ${ }^{\mathrm{c} R a d i a t i o n}$ Oncology, ${ }^{\mathrm{d} P a t h o l o g y,}$ \\ and ${ }^{e}$ Radiology, Ondokuz Mayıs University Faculty of Medicine, Samsun, Turkey
}

\section{Key Words}

Mucinous cystadenocarcinoma $\cdot$ Breast $\cdot$ Estrogen receptor $\cdot$ Treatment

\begin{abstract}
Primary mucinous cystadenocarcinoma (MCA) of the breast was first described by Koenig and Tavassoli in 1998. To our knowledge, only 9 cases of MCA of the breast have been reported. The optimal treatment of MCA could not be defined yet. This article aims to increase the knowledge about this rare variant of breast cancer and to review the literature.
\end{abstract}

\section{Introduction}

Mucinous cystadenocarcinoma (MCA) is a very rare tumor of the breast. In the literature, only a handful of cases have been reported [1]. These tumors are a rare, clinicopathologically distinct type of primary breast carcinoma that should be distinguished from typical mucinous (colloid) carcinomas of the breast and, more importantly, metastases from other sites such as the pancreas and ovaries [2-4].

\section{Case Report}

A 52-year-old premenopausal woman presented with a mass in her left breast. There were neither nipple discharge nor skin retraction. She has no children and no history of hormonal treatment or tumor history in the family. Physical examination revealed a big firm tumor of $5 \times 10 \mathrm{~cm}$ in size in the 


\begin{tabular}{|c|c|c|c|}
\hline $\begin{array}{c}\text { Cose Reports in } \\
\text { Bnatily }\end{array}$ & $\begin{array}{l}\text { Case Rep Oncol 2009;2:210-216 } \\
\text { D0I: } 10.1159 / 000253866\end{array}$ & Published online: November 14, 2009 & $\begin{array}{l}\text { (c) } 2009 \text { S. Karger AG, Basel } \\
\text { ISSN } 1662-6575 \\
\text { www.karger.com/cro }\end{array}$ \\
\hline
\end{tabular}

breast. No axillary lymph node involvement was noticed. Mammography showed a well-defined multilobular mass in the left breast involving nearly the whole breast. The tumor was well-defined and had neither spiculated margins nor intralesional microcalcification (fig. 1).

Fine-needle aspiration biopsy revealed a benign mass that had suspicious malignant findings. Therefore, an excisional biopsy was performed. Gross inspection revealed a grey, gelatinous, multilocular cystic tumor containing mucinous material with some necrosis. Microscopically, variably sized cystic spaces were observed. The tumor was confined with atypical cells containing

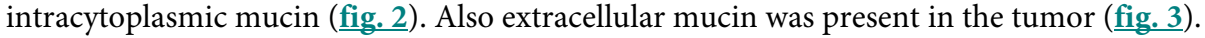

The tumor was diagnosed as mucinous cystadenocarcinoma (MCA). After this diagnosis, an abdominopelvic ultrasonography was performed and proved to be normal. There was no pathology in the ovaries and pancreas. Modified radical mastectomy was performed. There was residual tumor in the specimen and tumor in the nipple, but no skin infiltration. The specimen had atypical ductal hyperplasia. In the axillary dissection material, there were 10 reactive lymph nodes. Immunohistochemically, the tumor cells were positive for estrogen receptor (ER; 95\%) (fig. 4), and completely negative for progesterone receptor (PR) and C-erb-B2 receptor. Also cytokeratin 7 (CK7), 20 (CK20), and chromogranin immunoreactivities were negative.

According to the American Joint Committee on Cancer Staging System [6], the tumor was staged as Stage IIA (T3N0M0). Because of ER positivity, tamoxifen was given. The patient has been followed for 24 months without chemotherapy (CT) and radiotherapy (RT) and has no metastasis or recurrence.

\section{Discussion}

Mucin-producing breast carcinomas have been broadly categorized into mucinous carcinoma, in which malignant cells are suspended in extracellular mucin, and signet ring cell carcinoma, in which the mucin is predominantly intracellular. Primary MCA of the breast, however, demonstrates both intracellular and extracellular mucin and is histologically similar to primary MCA of the pancreas and ovary [7]. It may be misinterpreted as a benign lesion because the small biopsy specimens may only consist of tumor cells with bland nuclei [8]. This case is the 10th case of breast MCA. In the literature, all the known MCA cases showed loss of ER and PR expression, but this case shows that MCA can also be ER-positive. According to the literature, the prognosis seems good even in tumors with a size of $10 \mathrm{~cm}$ [8].

Ovary and pancreas mucinous adenocarcinoma are usually CK7+/CK20+, while MCA of the breast is usually CK7+ and CK20-. The antibody panel including CK7 and CK20 may be useful to make a differential diagnosis between primary and metastatic mucinous tumors, but detailed clinical evaluation is necessary [8]. Neuroendocrine differentiation with expression of chromogranin is frequently demonstrated in mucinous carcinoma, but not in all MCAs nor in our case [8].

The MCAs of the breast in the literature, including the present case, are presented in table 1. Notably, in the 9th case reported in the literature, too, both ER and PR in the primary MCA of the breast were negative, whereas ER and PR in the MCA were often expressed [10]. Since the MCAs were ER- and PR-negative, the hypothesis can be made that these tumors have been developed free from estrogen stimulation [5]. Therefore, no patients received hormonotherapy. The fact that our case was stained highly ER-positive led to the idea that these tumors are also estrogen-sensitive, as the other primary breast tumors. Therefore, when determining the treatment of patients presenting with this kind of tumor, hormonotherapy should also be considered as an option. This inhibits both translocation and nuclear binding of tamoxifen receptor, thereby preventing estrogen responsive genes from transcriptional activation. Tamoxifen induces apoptosis and prevents tumor growth, protein inhibits kinases and provides the regulation of tumor growth factors $[11,12]$. Moreover, insulin growth factor affects regulatory cytokines such 
as TGF $\beta$, and basic fibroblast growth factor inhibits angiogenesis [13]. In in vivo studies, it was determined that the level of VEGF that has an impact on angiogenesis was also decreased [13-15]. We hoped that tamoxifen would be effective in our patient considering all the mechanisms mentioned above. ER, PR and c-erb-B2 is stained negative in MCA [5, 8]. Our case was stained ER-positive and PR- and c-erb-B2-negative. As it is known, ER, PR and c-erb-B2 triple negative breast tumors are associated with poor prognosis [16]. Indeed, it could be expected that the receptors of these tumors, which are nonmetastatic, without local recurrence and with good prognosis, would be positive.

Patients were between 47 and 96 years old and older patients were likely to develop MCA $[5,8]$. Patients were often postmenopausal and the age of average incidence was 68 [8]. Our patient was also postmenopausal.

MCA was noted to originate from the main ductus close to the papilla [5, 8]. Papilla involvement in the mammographic images and histopathological investigation in our case also supported this hypothesis.

Out of 10 patients, 2 developed lymph node metastasis, which is considered to be associated with the long history of the primary tumor $[2,5]$. Our patient had a short history and presented with no axillary lymph node metastasis. Honma et al. [5] treated a patient presenting with a 6-cm conglomerate of axillary metastatic lymph nodes with mastectomy (M) and lymph node dissection (LND), and after 46 months of follow-up without adjuvant therapy, the patient died from a disease other than MCA. These facts lead to the assumption that axillary lymph node metastasis is not associated with poor prognosis.

The general treatments were M and LND; however, 3 patients underwent lumpectomy. With respect to postoperative adjuvant therapy, 1 patient [2] received RT, while 2 patients $[2,8]$ received CT. In the study of Koenig and Tavassoli [2], a third case presenting with a 8.5-cm diameter sarcomatous component was exposed to adjuvant CT and RT after M and LND. The CT given to this patient was a combination including antracyclin, which seems logical as it included a sarcomatous component. This patient presented with no disease during an 11-month follow-up. The second patient [8] receiving CT in the literature was the one presenting with a $3-\mathrm{cm}$ diameter tumor but no nodal metastasis, and undergoing M and LND. RT indication was not suggested when the patient was assessed for RT to the chest wall.

In the literature, a patient presenting with a 19-cm tumor and lymph node metastasis was treated with M and LND, but did not receive CT and RT [2]. If the case had been assessed classically, as the other invasive breast cancer types, this patient would have been delivered RT and CT. However, during a 24-month follow-up, no disease was observed in the patient. The other patient presenting with lymph node metastasis [5] and with a $2-\mathrm{cm}$ diameter tumor was treated with lumpectomy and LND, but did not receive RT and CT, and the patient died from a disease other than MCA at the end of a 46-month follow-up. This contributes to the hypothesis that surgery is indeed sufficient for the treatment of this disease. In the study of Rosen et al. [3], the patient presenting with a 6-cm diameter tumor and undergoing mastectomy and LND, but not receiving adjuvant therapy, did not experience any symptoms related to this disease in a 9-year follow-up.

As indicated in table 1, for the 4th, 6th and 9th patients undergoing breast-conserving surgery, for the first patient presenting with a $19-\mathrm{cm}$ diameter tumor, and for the patients presenting with metastatic axillary lymph nodes $[3,8]$ RT was not suggested. None of 
these patients developed locoregional recurrence, and therefore, we should pay attention when suggesting RT for these patients. Compatible with this, in the light of current literature we did not suggest CT and RT for our patients. Because ER was highly positive in our patient and because we found invasive atypical epithelial hyperplasia, tamoxifen was started.

Although it is not sufficient to discuss only a few patients with good prognosis of these rare breast tumors, it can be seen that the patients were not affected by CT and RT. No recurrence or death related to disease occurred in any of the patients [8]. The follow-up period reported was 9 years at the most and 8 months at least. Although the nature of breast MCAs is invasive, these carcinomas are associated with a good prognosis [7].

However, it is necessary to differentiate primary MCA of the breast from other benign lesions of the breast releasing the typical mucin and mucinous carcinoma $[5,7,8]$. More importantly, it is necessary to conduct detailed clinical and histopathological investigations in order to differentiate the organs in the abdomen and pelvis from MCA metastases in the pancreas and ovaries $[2,5,8]$.

In conclusion, we need to observe a certain disease progression and therefore more cases to answer the question whether only surgery or, as in other invasive breast tumors, a combination of surgery, CT and RT is to be used for the treatment of this rare breast cancer with good prognosis.

Table 1. Summary of clinicopathologic features

\begin{tabular}{|c|c|c|c|c|c|c|c|c|c|c|}
\hline $\begin{array}{l}\text { Case } \\
\text { No. }\end{array}$ & $\mathrm{R}$ & Age & $\begin{array}{l}\text { Tumor } \\
\text { size, } \mathrm{cm}\end{array}$ & LNM & Treatment & Follow-up & ER & PR & CK7 & CK20 \\
\hline 1 & 2 & 54 & 19.0 & + & M, LND & 24 months $^{\mathrm{a}}$ & - & - & + & - \\
\hline 2 & 2 & 67 & 2.3 & - & M, LND & 22 months $^{\mathrm{a}}$ & - & - & + & - \\
\hline 3 & 2 & 49 & 8.5 & - & M, LND, CT, RT & 11 months $^{\mathrm{a}}$ & - & - & + & - \\
\hline 4 & 2 & 61 & 0.8 & - & Lumpectomy, LND & b & - & - & + & - \\
\hline 5 & 4 & 74 & 10 & - & M, LND & 2 years $^{\mathrm{a}}$ & - & - & + & - \\
\hline 6 & 5 & 96 & 2.0 & + & Lumpectomy, LND & 46 months & - & - & + & - \\
\hline 7 & 3 & 79 & 6.0 & - & M, LND & 9 years* & - & - & + & - \\
\hline 8 & 8 & 65 & 3.0 & - & M, LND, CT & 8 months $^{\mathrm{a}}$ & - & - & + & rare \\
\hline 9 & 7 & 51 & 4.0 & - & Lumpectomy & b & - & - & + & - \\
\hline Present case & & 52 & 10.0 & - & M, LND, TMX & 24 months $^{\mathrm{a}}$ & + & - & - & - \\
\hline
\end{tabular}

LNM = Lymph node metastasis; $\mathrm{M}$ = mastectomy; LND = lymph node dissection; $\mathrm{CT}$ = chemotherapy; $\mathrm{RT}=$ radiation therapy; TMX $=$ tamoxifen. ${ }^{\mathrm{a}}$ Alive with no evidence of disease; ${ }^{\mathrm{b}}$ unknown. ${ }^{*}$ Died of disease other than MCA. 


\begin{tabular}{|c|c|c|c|}
\hline $\begin{array}{r}\text { Case Reports in } \\
\text { Encisily }\end{array}$ & $\begin{array}{l}\text { Case Rep Oncol 2009;2:210-216 } \\
\text { D0I: } 10.1159 / 000253866\end{array}$ & Published online: November 14, 2009 & \begin{tabular}{|l} 
@) 2009 S. Karger AG, Basel \\
ISSN 1662-6575 \\
www.karger.com/cro
\end{tabular} \\
\hline
\end{tabular}

Fig. 1. Mediolateral oblique mammographic graphs of the left breast: a well defined multilobular mass involving the whole breast which has neither spiculated margins nor intralesional microcalcification.

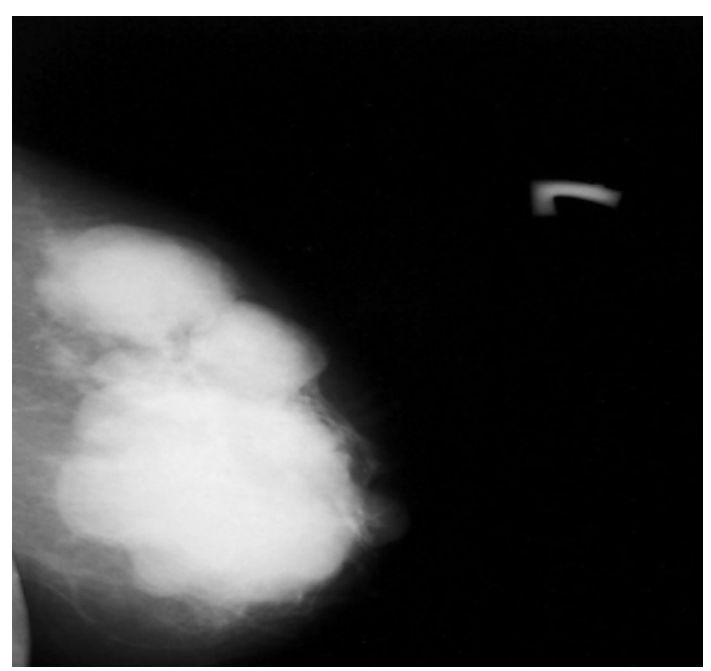

Fig. 2. The extracellular free mucin in the tumor. $\times 100$. HE.

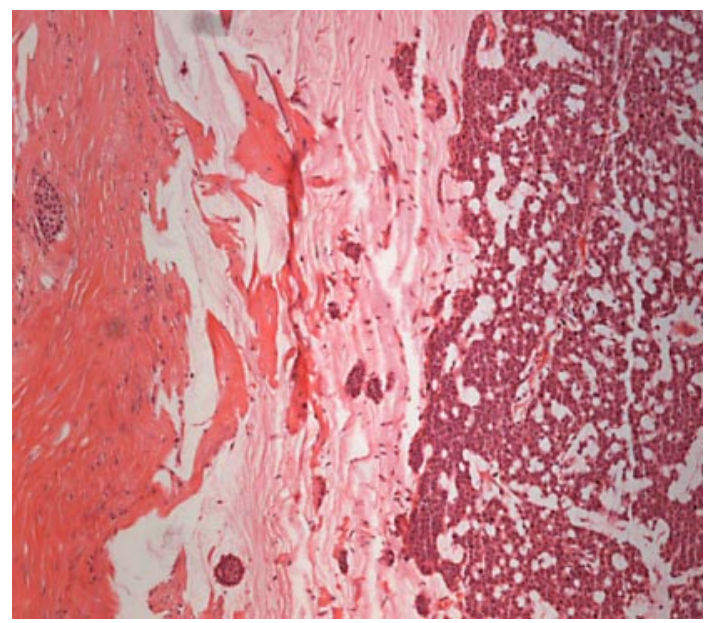


Fig. 3. The intracytoplasmic mucin in the tumor.

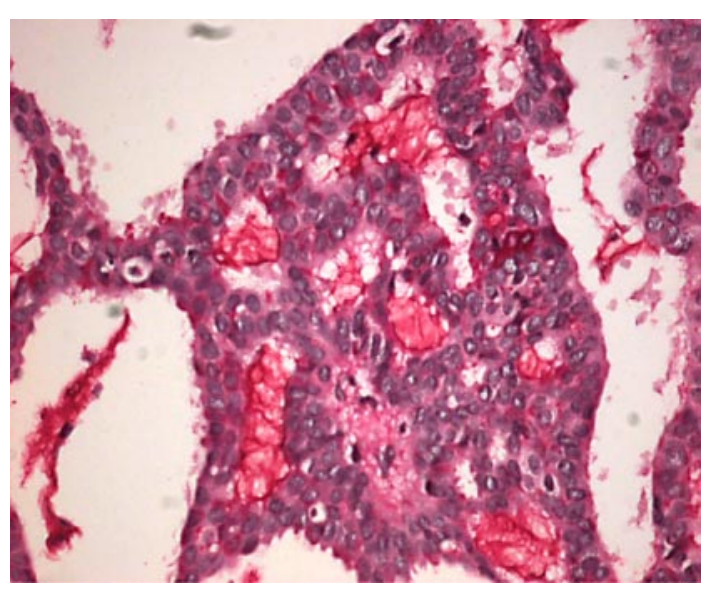

Fig. 4. Tumor of cells positive for estrogen receptor. $\times 400$.

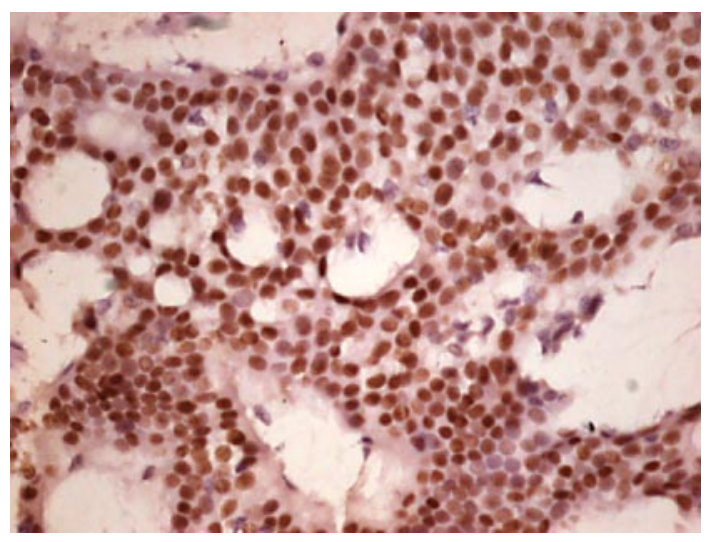




\section{References}

1 Tan PH, Tse GMK, Bay BH: Mucinous breast lesions: diagnostic challenges. J Clin Pathol 2008;61:11-19.

2 Koenig C, Tavassoli FA: Mucinous cystadenocarcinoma of the breast. Am J Surg Pathol 1998;22:698-703.

3 Rosen PP, Scott M: Cystic hypersecretory duct carcinoma of the breast. Am J Surg Pathol 1984;8:31-41.

-4 Domoto H, Terahata S, Yamazaki T, et al: Mucinous cystadenocarcinoma of the breast showing sulfomucin production. Histopathology 2000;36:567-569.

-5 Honma N, Sakamoto G, Ikenaga M, Kuroiwa K, Younes M, Takubo K: Mucinous cystadenocarcinoma of the breast. A case report and review of literature. Arch Pathol Lab Med 2003;127:1031-1033.

6 Singletary E, Allerd C, Ashley P, et al: Revision of the American Joint Committee on Cancer Staging System for breast cancer. J Clin Oncol 2002;20:3628-3636.

7 Coyne JD, Irion L: Mammary mucinous cystadenocarcinoma. Histopathology 2006;49:659-660.

8 Chen WY, Chen CS, Chen HC, Hung YJ, Chu JS: Mucinous cystadenocarcinoma of the breast coexisting with infiltrating ductal carcinoma. Pathology international 2004;54:781-786.

9 Scopsi L, Andreola S, Pilotti S, et al: Mucinous carcinoma of the breast. A clinicopathologic, histochemical, and immunocytochemical study with special reference to neuroendocrine differentiation. Am J Surg Pathol 1994;18:702-711.

10 McCarty KS Jr, Barton TK, Fetter BF, et al: Correlation of estrogen and progesterone receptors with histologic differentiation in mammary carcinoma. Cancer 1980;46:2851-2858.

11 Kang Y, Cortina R, Perry RP: Role of c-myc in tamoxifen-induced apoptosis in estrogen-independent breast cancer cells. J Natl Cancer Inst 1996;88:279-284.

12 Blackwell K, Haroon ZA, Shan S, et al: Tamoxifen inhibits angiogenesis in estrogen receptor-negative animal models. Clin Cancer Res 2000;6:4359-4364.

13 McNamara DA, Harmey J, Wang JH, Kay E, Walsh TN, Bouchier-Hayes DJ: Tamoxifen inhibits endothelial cell proliferation and attenuates VEGF-mediated angiogenesis and migration in vivo. Eur J Surg Oncol 2001;27:714-718.

14 da Silva BB, da Silva RG Jr, Borges U, et al: Quantification of angiogenesis induced in rabbit cornea by breast carcinoma of women treated with tamoxifen. J Surg Oncol 2005;90:77-80.

15 Garvin S, Dabrosin C: Tamoxifen inhibits secretion of vascular endothelial growth factor in breast cancer in vivo. Cancer Res 2003;63:8742-8748.

16 Santillan AA, Kiluk JV, Cox JM, Meade TL, Allred N, Ramos D, King J, Cox CE: Outcomes of locoregional recurrence after surgical chest wall resection and reconstruction for breast cancer. Ann Surg Oncol 2008;15:1322-1329. 